\title{
When the Language Discovers Hidden Meanings in the Collective Unconscious: Four Conceptual Metaphors in the Montenegrin Language
}

\author{
Miomir Abovic \\ Department of Montenegrin Language, University of Montenegro, Podgorica, Montenegro
}

Email address:

abovicmiomir@t-com.me

\section{To cite this article:}

Miomir Abovic. When the Language Discovers Hidden Meanings in the Collective Unconscious: Four Conceptual Metaphors in the Montenegrin Language. International Journal of Language and Linguistics. Vol. 9, No. 1, 2021, pp. 24-31. doi: 10.11648/j.ij11.20210901.14

Received: February 18, 2021; Accepted: March 13, 2021; Published: March 22, 2021

\begin{abstract}
In this paper, four conceptual metaphors very frequently used in the Montenegrin language are analyzed. These are conceptual metaphors: Negotiation is Boxing Match, Stone is Weak, Bad, Low-Quality, Humorous is Bloody and Capital is a Woman (During Intercourse, with an Intention for Procreation). The mentioned conceptual metaphors have entered the focus of our scientific interest because they reveal some very important facts about the Montenegrin mentality. We can say that these facts are immanent to the way of thinking of the average resident of Montenegro to the extent that they are firmly woven into the linguistic expression. These conceptual metaphors can be found in all functional styles of the Montenegrin language, and, most importantly, they are most often used in everyday language. The conceptual metaphors we deal with in this paper, however, are not only related to the way of thinking of the inhabitants of Montenegro, but are, potentially, also part of the universal way of functioning of the human mind. In the explication of the mentioned conceptual metaphors, we will apply the methodology of cognitive linguistics, and above all, we will focus on the theory of conceptual metaphor. The literature on the phenomenon of conceptual metaphor in contemporary world and domestic linguistics is extremely large and diverse. In our research and theoretical foundation of the concept of conceptual metaphor, we will start, of course, from the now classic book by Lakoff and Johnson "Metaphors We Live By", and then we will add to this classical study in the continuation of the paper the insights that individual (cognitive) linguists have gained about conceptual metaphor in the last twenty years.
\end{abstract}

Keywords: Cognitive Linguistics, Conceptual Metaphor, Montenegrin Language, Bloody, Fertilization

\section{Introduction}

Given the quantum of literature on conceptual metaphor, the widespread knowledge on this phenomenon, and the (relatively) well-comprehension of conceptual metaphor in (cognitive) linguistics literature, the repetition of basic facts about conceptual metaphor may seem (even) tasteless. However, it is necessary to do this at the beginning of work such as this. So we have to go back to 1980 when George Lakoff and Mark Johnson published the book Metaphors We Live $B y$, a book in which they theoretically funded the concept of conceptual metaphor. The first major discovery that Lakoff and Johnson made in this book concerns the ontological status of the conceptual metaphor. "We have found "that metaphor is pervasive in everyday life, not just in language but in thought and action; our ordinary conceptual system, in terms of which we both think and act, is fundamentally metaphorical in nature" [8]. Croatian linguists Milan Mateusz Stanojevic and Renata Geld say something similar to Lakoff nad Johnson: "Metaphorization and metonymization are two cognitive processes that are closely related to language. Metaphorization is our ability to talk and conclude about one thing as if it were something else entirely. So, we speak and think about one domain of our knowledge the target domain - as if the other domain of our knowledge is the original domain... Both metaphor and metonymy are conceptual phenomena, and their linguistic expression (eg grammar) is also important for their linguistic realization. Secondly, both depend on our usual experience - so we can use them to establish conventional connections - as well as on our communication needs - so these connections can serve different communication needs in different cases [5]. 
Thus, metaphor is not only an artistic creation related to a stylistically saturated language - or to the language at all - it is more immanent to our conceptual system, which underlies thinking and acting. Lakoff and Johnson, however, go a step further, explaining that the concepts that govern our thought are not just matters of the intellect, they also govern our everyday functioning, down to the most mundane details [8]. „Our concepts structure what we perceive, how we get around in the world, and how we relate to other people. Our conceptual system thus plays a central role in defining our everyday realities. If we are right in suggesting that our conceptual system is largely metaphorical, then the way we think, what we experience, and what we do every day is very much a matter of metaphor" [8].

Lakoff and Johnson postulate the assumption that metaphor is, in fact, one of the fundamental organizing principles of our thinking. This, again, means that subjectiveobjective reality - thus the phenomena of the external world and our inner life - are often conceptualized not directly (as these phenomena per se and strictly separated from other phenomena of reality), but rather mediated through some other phenomena. Ultimately, we can say that the conceptual metaphor indicates that the process of thinking and conceptualizing a particular occurrence - at least to some extent - is based on operations of connection, association, and analogy with another phenomenon. Thereby, conceptual metaphors are ,unidirectional: they go from concrete to abstract domains; the most common source domains are concrete, while the most common targets are abstract concepts. In this way, conceptual metaphors can serve the purpose of understanding intangible, and hence difficult-tounderstand, concepts" [6]. The statement that conceptual metaphors serve to better understand the intangible and, therefore, concepts that are difficult to understand, must be more carefully formulated. Thus, for example, John Taylor is skeptical regarding Lakoff and Johnson's thesis that abstract domains cannot be conceptualized by their own terms, but must be approached through metaphor, and that metaphor is not only a way of speaking, but immanent to abstract thinking. He notes the following: "In order for a target domain to be subject to mapping from a source domain, there has to be some prior conceptualization of the target domain. We need to know, at very least, which elements of the source domain can map into which elements of the target domain, and this presupposes that the target domain already has some initial 'pre-metaphorical' structure. This is not to deny that metaphor can enrich the target domain and our conceptualization of it, and even influence the way we behave with respect to it. Still, it is implausible that it is metaphor that creates our conceptions of reasoning, time, morality, and so on" [14]. In further Taylor refers to Grady's assertion that the initial motivation for metaphorical mapping is not really the need to understand the target domain, but the need to symbolize our conceptualizations in a way that others can understand (we will take a look at Joseph Grady's views on the conceptual metaphor further in this paper). MateuszMilan Stanojevic is on the trail of Taylor's reflections:
"Although the conceptual metaphor helps us to understand a target domain, such as the target domain LOVE, we already have some (non-metaphorical) knowledge about that domain. For example, we already know that it is related to a feeling, we know that we feel this towards another person, we know that our feelings (including love) are not clearly and unambiguously visible to others (e.g. we can only assume that someone is in love from numerous signs, but none of the signs alone is enough to determine it clearly and unmistakably), we know that some feelings (as well as love) can hardly be controlled by the reason (e.g. we cannot decide that we will fall in love with someone). For some conceptual metaphor to be possible, our knowledge of the source domain must in some way coincide with the knowledge of the target domain; that is, they must not be completely contrary to the knowledge of the target domain" [12]. Therefore, when it comes to conceptual metaphor, it is better to speak about the foundation of the metaphor in cognitive-linguistic vision instead of a (more thoroughly) understanding of unmaterial concepts using the original domains. This, speaking of the basis for the metaphor, emphasizes Kovecses himself. Unlike the traditional metaphor view - within which source selection assumes an objective, the literal and pre-existing similarity between the source and target domains- „,cognitive linguistics view maintains that the selection of source domains depends on human factors that reflect nonobjective, nonliteral, and nonpreexisting similarities between a source and target domain. These are called the experiential bases or motivation of conceptual metaphors. Some of the common kinds of such similarities include: (1) correlations in experience, (2) perceived structural similarity, (3) perceived structural similarity induced by basic metaphors, (4) source being the root of the target. In this last case, the source may be either the biological or the cultural root of the target" [6] or, by words of Vyvyan Evans: "Hence, Lakoff nad Johnson use the term metaphor more inclusively than has traditionally been the case. This follows as they argue that linguistic metaphors are surface manifestations of underlying cognitive associations, which presumably inhere ni long-term memory, relating often diverse bodies or domains of conceptual knowledge. That is, linguistic behaviour that is metaphoric is a consequence of sets of stable cross-domain conceptual mappings, conceptual metaphors, which license the patterns evident in language use" [3]. "The metaphor is not just a matter of language, but of thought nad reason. The language is secondary. The mapping is primary, in that it sanctions the use of source domain language nad inference patterns for target domain concepts" [4].

When we talk about the phenomenon of conceptual metaphor, we are talking- as we've seen in previous citationabout the connection between two domains: the source and the target domain. This is why the conceptual metaphor is defined as one of the cognitive processes of constructing meaning on the basis of which we connect two conceptual domains: the source domain and the target domain" [12]. More specifically, the conceptual metaphor compares "two domains of knowledge (based on our ability to compare), and 
based on the above comparison, we come to some links between those domains. We call these links between domains "mapping" [12]. What is more important to emphasize in the introductory part is that in the relationship between the source and target domains, the point is on "the asymmetric relationship: the original domain is one that we have "greater" knowledge of because we use the original domain to explain some feature of the target domain. In order to call the link between the two domains a conceptual metaphor, there must be sufficient distinction between the source and target domains - the source and target domains must belong to parts of our experience that we perceive as suite different" [12]. In one of his works Kovecses also emphasizes some facts which are important for our research: "The point is that the primary metaphors are likely to be universal, whereas the complex ones that are formed from them are much less likely to be so. Cultures greatly influence what complex conceptual metaphors emerge from the primary metaphors. In my view, all of this surely part of the explanation, but there is a lot more that must be added to make the cognitive linguistic view of metaphor a more comprehensive nad sophisticated account of both the universality and the variation of metaphor. In particular, I will suggest, among other things, the following: a) universal experiences do not necessarily lead to universal metaphors; b) bodily experience may be selectively used in the creation of metaphors; c) bodily experience may be overridden by both culture nad cognitive processes; d) primary metaphors are not necessarily universal; e) complex metaphors may be potentially or partially universal; f) metaphors are not necesarilly based on bodily experiencemany are based on cultural considerations and cognitive processes of various kinds" [7]. Now, when we epistemologically have grounded our theoretical postulates, we may cross on concrete material of Montenegrin Language.

\section{Conceptual Metaphor Negotiation Is Boxing Match}

The first conceptual metaphor that will be analyzed in this paper is the conceptual metaphor NEGOTIATION IS BOXING MATCH. We extract this conceptual metaphor from statements such as: "The second round of negotiations between the West and Iran has begun." The conceptual metaphor NEGOTIATION IS BOXING MATCH is semantically close to the very frequent conceptual metaphor ARGUMENT IS WAR, which is found in statements such as "Pobio sam sve njegove argumente" (I killed all his arguments), "Bio sam apsolutni pobjednik u raspravi s njom" (I was the absolute winner in discussion with her), "Moje primjedbe pogodile su u centar" (My remarks hit the center), etc.

Like the conceptual metaphor, ARGUMENT is WAR, the conceptual metaphor NEGOTIATION IS BOXING MATCH also belongs to the so-called structural metaphors, which allow us to do much more than merely orient the concepts, refer to them, quantify them, etc., as is the case with simple orientation and ontological metaphors. Moreover, they allow us to organize the other concept with the help of one highly structured and clearly outlined concept. Just like orientation and ontological metaphors, structural metaphors are grounded in systematic correlations within our experience (Lakoff, Johnson 2003: 62). So, as with war we are not just talking about discussions, also with boxing we are not talking only about negotiations. We perceive the person/persons with whom we are negotiating as a rival, opponent; in negotiations, just like in a boxing match, one side can win or lose; in negotiations, again as in a boxing match, we devise tactics and strategies for achieving our goal. In the negotiations there is no physical calculation of rivals like in a boxing match (at least not yet), but there is a kind of verbal "fight": opposing arguments and counterarguments. A lot of what people do in negotiations is structured, therefore, by the concept of a boxing match. Like the conceptual metaphor ARGUMENT IS WAR, the conceptual metaphor NEGOTIATION IS BOXING MATCH is ,is one that we live by in this culture; its structures the actions we perform in arguing" [8].

In that sense, talking about metaphor ARGUMENT IS WAR and the same can be said about metaphor NEGOTIATION IS BOXING MATCH - Lakoff and Johnson make an interesting observation: they suggest that we try to imagine a culture where discussions are not viewed in terms of war. "Imagine a culture where an argument is viewed as a dance, the participants are seen as performers, and the goal is to perform in a balanced and aesthetically pleasing way. In such a culture, people would view arguments differently, experience them differently, carry them out differently, and talk about them differently. But we would probably not view them as arguing at all: they would simply be doing something different. It would seem strange even to call what they were doing "arguing." Perhaps the most neutral way of describing this difference between their culture and ours would be to say that we have a discourse form structured in terms of battle and they have one structured in terms of dance" [8].

Structuring negotiation as a boxing match in the Montenegrin (Bosnian/Croatian/Serbian) language, however, has consequences even at a level deeper than just cultural conditioning and experiencing one thing through another. Conceptual metaphor NEGOTIATION IS BOXING MATCH, by which we speak about the negotiations, most speakers of our language are not, indeed, aware; that metaphor is in our concept of negotiation itself. What we want to say is that this metaphor contains ("hides in itself") certain deep anthropological facts: some essential anthropological insights, at least about the community in the language that has been used frequently. Negotiations are not a fight, but they are not conceptualized only by the term boxing match. Namely, the phenomenon of negotiation is the result of the civilizational maturation of the human species; negotiations are a form of social practice created by the growth of the rational powers and capacities of the human being. However, as a rational attempt to resolve a dispute between the two parties peacefully and by agreement, the negotiations "grow" and in 
fact rest on the basis of conflict - whether physical, war or conflict of another kind - and from the conflict essentially derive their "élan vital", it is no surprise that the matrix of physical conflict is dominant in conceptualizing this phenomenon.

We can say that the conceptual metaphor NEGOTIATION IS BOXING MATCH reflects, on the one hand, let's call it a synchronous state: that is, two parties that are still in dispute at the moment and struggling to get the best out of that dispute; only the struggle from the rougher plans was transferred to the field of verbal viewing. On the other hand, in the conceptual metaphor NEGOTIATION IS BOXING $\mathrm{MATCH}$ in our opinion, there is also a deeper aspect, a segment of human nature in general: the strength and deeprootedness of aggression and the need for physical conflict. The power and significance of this instinct - certainly one of the primordial, implies that the conceptual structuring of negotiations - that is, the phenomenon by which one tries to end a particular dispute - takes place in the coordinates of the phenomenon of physical confrontation.

\section{Conceptual Metaphor Stone Is Weak, Bad, Low- Quality}

Another conceptual metaphor we will deal within this paper is the conceptual metaphor STONE IS WEAK, BAD, LOW- QUALITY, which we extract from statements such as Kamene su ti ove smokve (These figs of yours are stony), Kameno ti je napravio taj krov (He made you that roof very stony), etc. The stone and the adjective derived from this noun can be a metaphor for some other negative phenomena, such as irrespective manner and ruthlessness. When it comes to conceptual metaphor: STONE IS WEAK, BAD, LOWQUALITY in Montenegrin language, it is important to distinguish two points. First, it is the strong geographical and cultural conditionality of this conceptual metaphor."Proučavanje kulture i specifičnosti pojedinih razdoblja (te specifičnosti metafora u njima) nužno je da bi se spoznala narav interakcije općih i specifičnih aspekata kulture i kognicije, te način na koji ljudi razmišljaju u stvarnim interakcijama [13]. Second, it is an appearance immanent to the conceptual metaphor - a phenomenon partial mapping that occurs in the literature about the conceptual metaphor.

The presence of the adjective kamen, $-a,-o$ (stony) in different metaphorical extensions in the Montenegrin language - given the geographical characteristics of Montenegro and the geographical conditions in which the majority of the Montenegrin population lives - is no surprise, on the contrary. The stone and karst terrain structures in the central and southern parts of Montenegro are the dominant characteristics of the environment: the harsh living conditions that in a way shape the psychological composition of the people living in that terrain and in that climate. Here arises the question: how the adjective kamen, $-a$, $-o$ (stony) in the Montenegrin language developed the metaphorical meaning of the weak, bad, the low-quality? This meaning became conventional, part of everyday speech usage, and the basis for generating the conceptual metaphor. This is where the phenomenon we mentioned before comes into play, ie. partial mapping. Kovecses notes the following: "Metaphorical mappings from a source to a target are only partial. Only a part of the source domain is utilized in every conceptual metaphor. We have called this partial metaphorical utilization. This partial structure of the source highlights, that is, provides structure for only a part of the target concept. We have called this metaphorical highlighting. The part of the target that falls outside the highlighted region is said to be hidden" [6]. Part of the original domain exploited in this conceptual metaphor comes from the experience of living on karst soil (recall, on this occasion, the recently cited Kovecses statement that the original domain can be either the biological or cultural root of the target domain): stony or rocky (soil) is barren (soil). And the infertile is necessarily perceived in the framework of negativity: therefore, as something weak, of low quality, bad. We can say that - when we talk about the conceptual metaphor STONE IS WEAK, BAD, LOW-QUALITY we are dealing with a kind of logical syllogism: STONY IS BARREN, INFERTILE IS WEAK, BAD, of LOWQUALITY $\rightarrow$ STONE IS WEAK, BAD, LOW-QUALITY. In this way, a combination of geographic and cultural determinants on one side and, on the other, certain internal laws related to the phenomenon of conceptual metaphor, formed a conceptual metaphor that largely represents the specificity of the Montenegrin language (the stone and the adjective kamen, -a, -o (stony) can, however, also be a metaphor for positive phenomena such as moral-character solidity, human permanence and reliability. In this respect, it is interesting to note the misinterpretation of the authors of the Dictionary of Croatian or Serbian language [10] by an example from the prose of S. M. Lubisha. Namely, as an example of the adjective kamen, -a, -o (stony) in his ( $\mathrm{S}$. Lubisha, prip. 167) metaphorical notion o vjeri, pa i o pouzdanom, vjernom čeladetu (of faith, and also of a reliable, faithful human) for the metaphorical use of the adjective kamen, -a, -o (stony) cite the use of this adjective in the sentence Ja sam ti kamena uzdanica (I am your stony pillar). It is obvious that the authors of this Dictionary did not know the use of the adjective kamen, -a, -o (stony) in the sense of weak, bad in Montenegrin dialect in that moment (since the 30 s of the nineteenth century until the First World War language in Montenegro was officially called Serbian, and it represented the dialect).

\section{Conceptual Metaphor: Humorous Is Bloody}

Another conceptual metaphor that we will cover in this paper is the one characteristic only for the Montenegrin language. It is a conceptual metaphor HUMOROUS IS BLOODY, which is extracted from the statement such as 
"Stomak me boli od smijeha, ovaj ludi Đuro je krvav" (Stomach is hurting me from laugh, this crazy Đuro is bloody). The question that arises here is: Where does the connection between humor and blood come from? Because, at first glance, we find here two conceptual domains that do not have many touching points. Among other things, due to this lack of transparency of the link between the source and the target domain, the conceptual metaphor HUMOROUS IS BLOODY represents so-called compound metaphors.

Vivian Evans and Melanie Green, referring to Joseph Grady and his influential study "Foundations of Meaning: Primary Metaphors and Primary Scenes"- state that Grady distinguishes two types of metaphor: primary metaphor and compound metaphor [2]. He noted that there is one potential contradiction within the theory of conceptual metaphor: the contradiction regarding the claim that the target domain possesses an invariant inherent structure that limits metaphorical mappings, and that this domain is at the same time abstract in the sense that it is not clearly delineated. According to the conceptual metaphor theory, the purpose of the metaphor is to map structure to abstract domains; however, if the target domain already has its invariant structure, the question is why does it require metaphorical structuring at all. Grady answers this question by establishing the so-called Primary Metaphor Theory.

As Evans and Grinova note, he rejects the view that the distinction between the target domain, on the one hand, and the original domain of metaphorical mappings, on the other, can be identified with distinction as abstract vs. concrete concepts. Instead, "Grady argues that the distinction between target and source relates to the degree of subjectivity rather than how clearly delineated or how abstract a concept is" [2]. In support of his own thesis, Grady cites examples of conceptual metaphors:

Similarity (Nearness)

Importance (Size)

Quantity (Vertical elevation)

Cause (Compelling force)

Change (Motion)

Desire (Hunger)

and states (according to Evans and Green) that "primary target concepts reflect subjective responses to sensory perception and represent 'judgments, assessments, evaluations and inferences' [2]. Evans and Green, considering Grady's views, state further that "from this perspective, target concepts like SIMILARITY, QUANTITY and DESIRE are not dismissed as 'abstract' but are recognised as being among the most fundamental and direct experiences we have as human beings. This explains why Grady describes them as 'primary'. The key distinction between target and source in Grady's theory is the primary source concepts relate to sensory-perpetual experience, while primary target concepts relate to subjective responses to sensory-perpetual experience [emphasis added]" [2].

Grady therefore claims that both, primary target and primary source domains, are equally basic and derived from real and directly experiences, and that primary metaphors - based on which complex metaphors are created - provide an "abstract" target domain with a structure that it "lacks". If the difference between the source and target domain cannot be reduced to the distinction between concrete and abstract concepts (in the Primary Metaphor Theory, just as in its general framework that constitutes the Theory of Conceptual Metaphor, the link between the source and target domain is a one-way link) the question is how Primary Metaphor Theory explains the mapping from the original to the target domain.

More specifically, a different explanation is needed for above mentioned one-way link, and the question that must be answered is: what is it that in Primary Metaphor Theory makes the one domain source domain and the other one target domain? In Primary Metaphor Theory, the mapping from the source to the target domain is explained as follows: "Because primary target concepts relate to subjective responses, they operate at a level of cognitive processing to which we have low conscious access. Primary target concepts are responses and evaluations, which derive from background operations. According to this view, the function of primary metaphor is to structure primary target concepts in terms of sensory images in order to foreground otherwise backgrounded cognitive operations. This is achieved by employing source concepts that are more accesible because they relate to sensory rather than subjective experience. Primary source concepts, which derive from external sensory experience, are said to have image content while primary target concepts, which are more evaluative and hence subjective in nature, are said to have response content [emphasis added] [2].

Unlike primary metaphors that are fundamental, complex metaphors are created by the union of primary metaphors. While the primary metaphors ,refer to simple aspects or dimensions of subjective experience, not confined to any particular, rich domain, but crosscutting these domains; not associated with particular, rich, scenarios but inhering within broad categories of scenarios. In other words, primary metaphors relate two 'simple' concepts from distinct domains. In contrast, compound metaphors relate entire complex domains of experience, like THEORIES ARE BUILDINGS" [2].

From the above-mentioned, the first difference between the primary and complex metaphors emerges: unlike the primary metaphors in which the source and target domains are linked by experiential correlations derived from human psychology and the environment that humans share (therefore the primary metaphors are suitable to represent cross-language universalities), complex metaphors, because they arise from a more detailed and specific structure of knowledge, are more culturally dependent, i.e. they are dependent on the individual culture [2].

Another difference between primary and complex metaphors is what Grady calls it poverty of mapping. "Because primary metaphors relate to relatively simple knowledge structures - in other words, concepts rather than conceptual domains - they are expected to contain no mapping gaps. In other words, because a primary metaphor 
maps one single concept onto another, there is no part of either concept that is 'missing' from the mapping. In contrast, the compound metaphor THEORIES ARE BUILDINGS relies upon two complex conceptual domains, each of which can be broken down into component parts" [2].

Grady, as quoted by Evans and Green, cites examples of the sentences *This theory has French windows and *The tenants of its theory are late in paying rent, in which the components of windows, tenants and rent are not mapping to the target domain. Thus, "cracks in mapping" is another feature of complex metaphors. Grady finally states the third characteristic of complex metaphors that distinguishes these from primary metaphors: the lack of a clear experiential basis. More specifically: while primary metaphors are created on the basis of a clear experience, metaphorical associations between the source and target domains of a complex metaphor cannot be observed; taking as an example the conceptual metaphor THEORIES ARE BUILDINGS Grady argues that "we can hardly claim that theories and buildings are closely correlated with one another in our everyday experience of the world. Although we often discuss theories in buildings, buildings are only incidentally associated with theories: we might just as easily discuss theories outdoors, in a tent or on a boat" [2].

The conceptual metaphor HUMOROUS IS BLOODY meets all the criteria that make a conceptual metaphor complex one. We can say that it was created in the process of composition of two primary metaphors: CHARACTERISTICAL FEATURES ARE BODY FLUIDS and PSYCHOLOGICAL IS SOMATIC. Both of these primary metaphors in the Montenegrin language can be confirmed by a number of examples. The conceptual metaphor CHARACTERISTICAL FEATURES ARE BODY FLUIDS is reflected by the examples like: Dragan je jedno veliko g...o, Dok mu ne ispuniš ono što traži, ne staje. Pravi je proliv. (Dragan is a big piece of $\mathrm{sh}^{*} \mathrm{t}$, until you don ${ }^{\mathrm{t}}$ give him what he's looking for, he won't stop. He is such diarrhea.); To je jedna sluz od čovjeka (It's one slime of a man) itd. The conceptual metaphor PSYCHOLOGICAL IS SOMATIC, however, we can find in the examples such as: Za bavljenje politikom treba imati dobar želudac (You need a good stomach to do politics); Mora mu se priznati da ima m.da (We have to admit, he has balls); Nemaš ni prst obraza (You don't even have a finger of honor); Ne brini, neće $t i$ $n i s ̌ t a$, to je jedna pi*ka (Don't worry, he won`t do anything to you, he is a pussy), etc.

The conceptual metaphor HUMOROUS IS BLOODY is culturally specific because it is exclusively related to the Montenegrin language. The poverty of the mapping feature is also immanent with this metaphor, because certain aspects related to blood do not map to the concept of humorous; we cannot say, e.g., Umro sam od smijeha od njegove priče, dijabetičan je (I died out of laughing while listening to his story, he is diabetic) or Puna je trigliceridâ, zamalo sam umrla od smijeha slušajući njene viceve (She is full of triglycerides, I almost died laughing while listening to her jokes).
Also, there is no clear experiential connection and transparency between the phenomenon of blood on the one hand and humorous on the other. The logical question then arises: how and why is (one's) humorous conceptualized precisely by the phenomenon of blood? In trying to explain the connection between these concepts, it is best to start with the explanation of the meaning of the noun blood and the adjective bloody. Veliki rječnik hrvatskoga standardnog jezika (The big dictionary of the standard Croatian language), from now on mentioned as VRHSJ, the most renowned capital lexicographic work in the Bosnian/Montenegrin/ Croatian/Serbian language area, defines the primary meaning of the noun blood as "red coloured body fluid that flows through blood vessels, transmitting on that way oxygen and food to cells and transporting waste matter" [15], while for the adjective bloody it states the following primary meaning: "which is covered with blood" [15].

Interestingly, in this dictionary, the jargon meaning of this adjective that is being cited is "which is excellent, perfect (bloody film / stunt; book is bloody)" [15]. And the Matica Srpska, Dictionary of the Serbian language under the heading of jargon, it defines the subtext of the adjective bloody as "extremely good, extraordinary, wonderful" [11]. Submeaning of this adjective: "humorous", which exists in the Montenegrin language, is not found in any of the above mentioned dictionaries.

Blood, then, is a life-giving substance: a substance that makes life possible. The blood splatter that has been denoted by the adjective bloody, in addition to the primary unpleasant condition in which someone is found after a certain degree of injury- may imply, secondarily, the fulfillment and largely coverage of a human being with a single life-giving fluid and substance. Exactly in this semantic component of the adjective bloody it is necessary to search for a link to the quality of humorous: in (subconscious) perception of Montenegrin language speakers, humorous is something that is life-giving, bracing, it is a life-breathing quality that makes the human being vital and charismatic (that our interpretation of the conceptual metaphor HUMOROUS IS BLOODY is on the right track confirms the data provided by etymology and symbology. The etymological dictionary of the Croatian language (Etimološki jezik hrvatskog jezika) explains the etymology of the word humor as follows: "Borrowed from eng. humor 'mood, humor', which is also borrowed through fr. from lat. ūmor 'fluid, moisture'. The word originally referred to the four bodily fluids (blood, mucus, yellow bile and black bile), which ancient and medieval physicians thought to determine the physical and mental health of human. In English, the meaning of 'mood' evolved into 'good mood' 'humor' [9]. Rječnik simbola (The Dictionary of symbols), in turn, confirms our explanation of the conceptual metaphor HUMOROUS IS BLOODY in the opposite direction to etymology: "Blood symbolizes all values related to fire, warmth and life, which are again associated with the sun. All that is beautiful, noble, exalted is associated with these values. Blood also belongs to the general symbolism of red. Blood is considered to be the carrier of life everywhere. 
Blood is life, the Bible says" [1]. The facts of etymology and symbology in different directions (etymologically in the direction from the source to the target domain, and symbolically in the direction from the target to the source domain) support our thesis on humorous as something bracing, vital, something that associative connects with blood as a life-enabling substance).

\section{Capital Is a Woman (During Intercourse, with an Intention for Procreation)}

The last conceptual metaphor that we will cover in this paper is the conceptual metaphor CAPITAL IS A WOMAN (during intercourse, with an intention for procreation). We extract this conceptual metaphor from the statement like: Crna Gora je veoma pogodno mjesto za oplodnju kapitala (Montenegro is a very suitable place for the fertilization of capital). This conceptual metaphor reflects one worrying metaphysical process: a metaphysical process that is being objectified in the value (less) system that underlies modern civilization. Namely, success- especially financially - is one of the fundamental defining determinants of the civilization in which we live; the more money- and consequently material possessions in general- one owns, he/she is considered more socially successful and respected. Therefore, it is not surprising that capital multiplication has become the obsession and mania of many people today. It's not even a surprise that the aforementioned fundamental determinant of the value (less) system of modern civilization became part of the conceptual apparatus of the local people, and then it embodied itself in language, in the form of a conceptual metaphor CAPITAL IS WOMAN (during intercourse, with an intention for procreation).

The monstrosity of the aforesaid conceptual metaphor is reflected in two directions: a) an act (intercourse) that belongs exclusively to the domain of the biological, the living - moreover, one of its immanent characteristics - is transposed into the realm of the inanimate; b) an act (intercourse) belonging to the realm of the intimate - indeed the domain of the most delicate intimacy - an act that (under normal circumstances) arises from the noblest of human feelings: the emotion of love - is transposed into the realm of the public, and into one of the dirtiest and lowest domains of the sphere of the public - into mercantile relations. In the conceptual system - and therefore in language - parallelism is established between, on the one hand, the domain of the love between man and woman - and the act of intercourse between two of them for the purpose of crowning that love by creating a child - and, on the other hand, the domain of business, that is, the accumulation of capital. Thus, the phenomenon of the lust for material goods is conceptualized in terms of the most intimate human act arising out of love between partners. As a result of the contamination and the interpenetration of these two domains, a monstrous metaphor emerges - the metaphor of desacralized and dehumanized civilization. Capital is perceived as a pregnant woman who, instead of a child, makes money. We would say the motive of Giger's provenance.

Unfortunately, we are not talking here about the motive of a Giger painting, nor the result of any artistic imagination, but about the part of the process of everyday thinking, incorporated into the mind to such an extent that the aforementioned conceptual metaphor has become quite ordinary and non-illogical linguistic construction. Greed, lust and hunger for material goods is, therefore, a phenomenon which is perceived as completely normal in modern civilization - everyday linguistic use is the best evidence of this.

\section{Conclusion}

Out of the four conceptual metaphors discussed, two of them - the second and the third one - represent the specificity of the Montenegrin language, while the remaining two - the first and the fourth one - are also found in the other three languages based on the Neo-Shtokavian dialect: Bosnian, Croatian and Serbian. All the conceptual metaphors discussed in this paper are interesting in that they reveal the mechanisms of functioning of the human mind in the process of conceptualization of certain phenomena, and two of them, related exclusively to the Montenegrin language are also interesting because of the cultural-geographical determinants of metaphorically associative flows.

We can say that this research (also) confirmed two things: a) Lakoff-Johnson's thesis stated at the beginning of the paper that our conceptual system through which we think and act is of metaphorical nature; b) that the relationship between the source and target domains within a conceptual metaphor is sometimes more and sometimes less transparent, but always cognitively relevant and interesting in the way to discover subconscious associations and meanings hidden in the depths of language.

Therefore, further scientific efforts in the study of conceptual metaphors in Montenegrin and Neo-Shtokavian languages in general (Bosnian, Croatian, Montenegrin and Serbian) will certainly bring to light a number of new interesting things related to this domain of our language and will enrich our knowledge of the language we speak.

\section{Resime}

When The Language Discovers Hidden Meanings In The Collective Unconscious: four conceptual metaphors in the Montenegrin language

The paper deals with the analysis of four conceptual metaphors very frequent in use in contemporary Montenegrin language: THE NEGOTIATION IS A BOX MATCH; STONE IS WEAK, BAD, LOW- QUALITY; HUMOROUS IS BLOODY; CAPITAL IS A WOMAN (during intercourse, with an intention for procreation). Through the analysis, we have tried to discover the deeper meanings hidden in these conceptual metaphors by using the conceptual apparatus of 
cognitive linguistics. We have also sought to determine that the aforementioned conceptual metaphors reveal certain regularities of the functioning of the human mind as well as a conditionality to cultural specificities.

\section{References}

[1] Chevalier, Jean; Gheerbrant, Alain, Rječnik simbola, Nakladni zavod Matice hrvatske, Zagreb, 1987.

[2] Evans, Vyvyan; Green Melanie, Cognitive Linguistics. An Introduction, Edinburgh University Press, Edinburgh, 2006.

[3] Evans, Vyvyan, How Words Mean, Oxford University Press, Oxford, 2010.

[4] Geeraerts, Dick (ed.), Cognitive Linguistics: Basic Readings, Mouton de Gruyter, Berlin-New York, 2006.

[5] Geld, Renata; Stanojević Mateusz-Milan, Strateško konstruiranje značenja riječju i slikom, Srednja Europa, Zagreb, 2018.

[6] Kövecses, Zoltán, Metaphor: A Practical Introduction, Oxford University Press, Oxford, 2002.
[7] Kövecses, Zoltán, Metaphor in Culture, Cambridge University Press, Cambridge, 2007.

[8] Lakoff, George; Johnson, Mark, Metaphors we live by. London: The University of Chicago Press. 2003.

[9] Matasović, Ranko; Pronk, Tijmen; Ivšić, Dubravka; RončevićBrozović, Dunja, Etimološki rječnik hrvatskoga jezika, Institut za hrvatski jezik i jezikoslovlje, Zagreb, 2016.

[10] Rječnik hrvatskoga ili srpskoga jezika, svezak 16, JAZU, Zagreb, 1896

[11] Rečnik srpskoga jezika, Matica srpska, Novi Sad, 2007.

[12] Stanojević, Mateusz-Milan, Konceptualna metafora: temeljni pojmovi, teorijski pristupi i metode, Srednja Europa, Zagreb, 2013.

[13] Šarić, Ljiljana; Brala-Vukanović, Maja, Slike jezika: temeljne kognitivnolingvističke teme, Jesenski i Turk, Zagreb, 2019.

[14] Taylor, John, Cognitive Grammar, Oxford University Press, Oxford, 2010

[15] Veliki rječnik hrvatskoga standardnog jezika, Školska knjiga, Zagreb, 2015. 